Vol.01/ No. 01

Pages: 27-37

https://www.irojournals.com/itdw/

DOI: https://doi.org/10.36548/jitdw.2019.1.004

\title{
EXPLORING DEVOPS: CHALLENGES AND BENEFITS
}

\author{
Dr. P P Joby, \\ Professor and Head, \\ Department of Computer Science and Engineering, \\ St. Joseph's College of Engineering and Technology, \\ Kerala. \\ jobypcse@gmail.com
}

\begin{abstract}
The continuous evolving of the information technology towards the enhanced agile and collective strides of working from the document driven working has turned the focus to the features of the information system development and the operations. These agile approaches have paved way for the concepts that provide an incorporated development and operations coined as the DevOps. The DevOps is an enterprise software development and viewed as the appropriate perception for the simultaneous distribution and the positioning of the working software. It enhances and modifies the relationship by promoting improved communication and the cooperation among the business unit. However the adoption of the Development and the Operation being a complex task the paper presents the review on the challenges and the benefits of the DevOps and also explores the DevOps to offer an enhancement in the adoption of the DevOps in the information systems.
\end{abstract}

Keywords: Development, Operation, DevOps, Agile Approaches, Challenges, Benefits benefits , Enhanced Communications and Co-operation, Traditional Approaches.

\section{INTRODUCTION}

The DevOps which is a combination of two words development and operation defines the art with a bulk of procedures that cause development and the operation crew to complete the software development to gather. It enables the organization to develop and enhance the product in swift way when compared to the traditional approaches used in the software development. This makes the DevOps [1] to gain a prominence at a high speed.

The DevOps [2] stimulates a team up between the development and the operation group to position the code to have a faster production in a way that is automated and the repeated. It enables the organization to speed up the delivery process in the application and the services. It ensures an improved customer service and competence in the market for the business. 
Journal of Information Technology and Digital World (2019)

Vol.01/ No. 01

Pages: 27-37

https://www.irojournals.com/itdw/

DOI: https://doi.org/10.36548/jitdw.2019.1.004

Generally the DevOps [3] is the deployment of the development and the information system operations with the enhanced cooperation and communication. The fig .1 shows the incorporation in the DevOps.

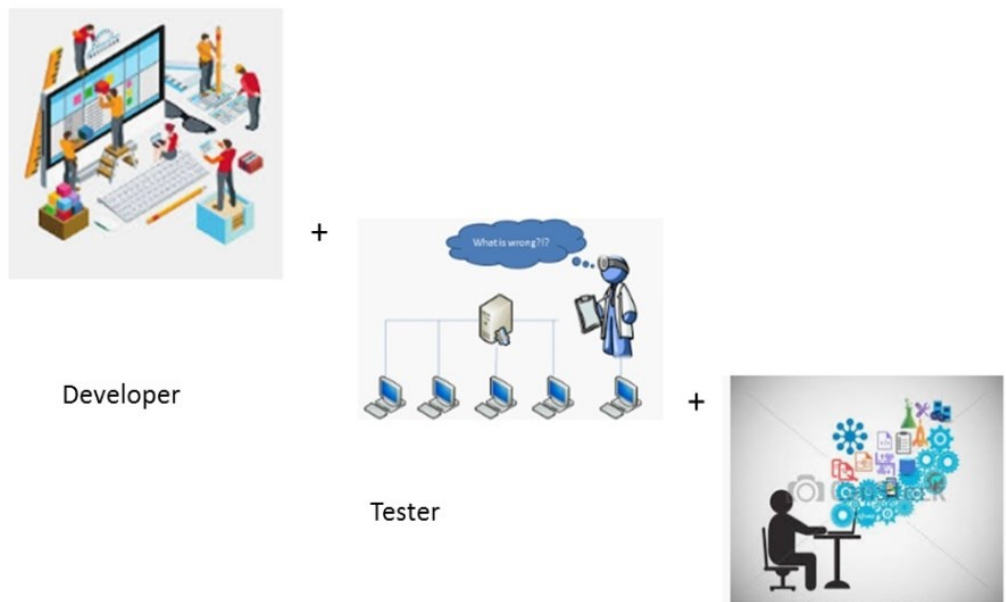

Operations

Fig.1. Incorporation in DevOps

The DevOps is a new province and a new way of intelligence in the software field, it is a trending idea and method to bridge the gap in the steps of the software development [4] the term DevOps was first coined in the between the years 2007 t0 2008 as an answer to the issues in the web services such as the Google, Netflix, Amazon, and many others. The collaboration of the development and operation was initially created for resolving the misconceptions and the confusions that prevails in between the developers and the IT operations, but later it incorporated the integration, quality, delivery, assurance along with the development, operations and other aspects relevant to it to enhance the capability of the organization. This makes the DevOps predominant among a wide range of organizations. The Fig. 2 provides the adoption rate of DevOps from the year 2015 to 2018 
Journal of Information Technology and Digital World (2019)

Vol.01/ No. 01

Pages: 27-37

https://www.irojournals.com/itdw/

DOI: https://doi.org/10.36548/jitdw.2019.1.004

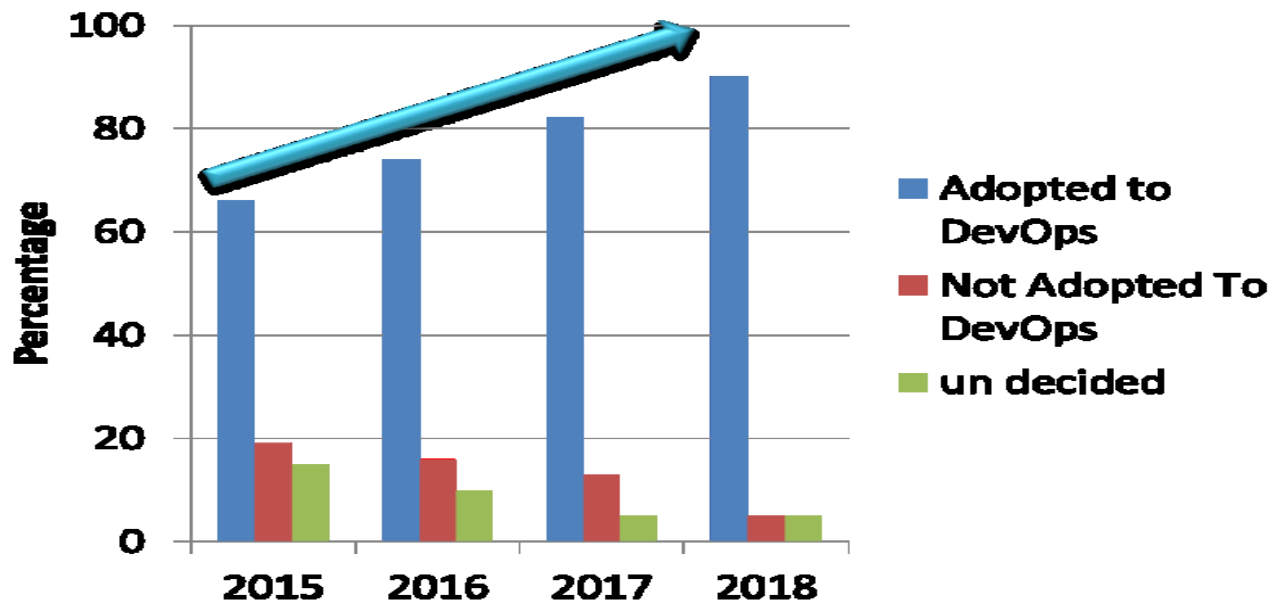

Fig .2 The Adoption Rate of DevOps

The Procedures in the DevOps emphasis on the perpetual deploying, monitoring, updation of the components along with the testing that is automated etc. The deploy organization, repository and the build tools are used in assisting the procedures of the DevOps[3] the fundamental forces driving making the DevOps capable are the people , process and the technology. The capability of the DevOps makes a broader range of applications to be adapted to the DevOps.

\subsection{IDEAL SKILL SET OF DEVOPS [8]}

The ideal skill set classifications are very essential for the ideal DevOps team for the effective delivery of the development and the operation so it includes the vital operational skills like analysis skills and the functional skills, social rational skills and the development skills for having a development and the operation that is successful. The fig. 3 below shows the ideal DevOps team Skill set Classification. 
Journal of Information Technology and Digital World (2019)

Vol.01/ No. 01

Pages: 27-37

https://www.irojournals.com/itdw/

DOI: https://doi.org/10.36548/jitdw.2019.1.004

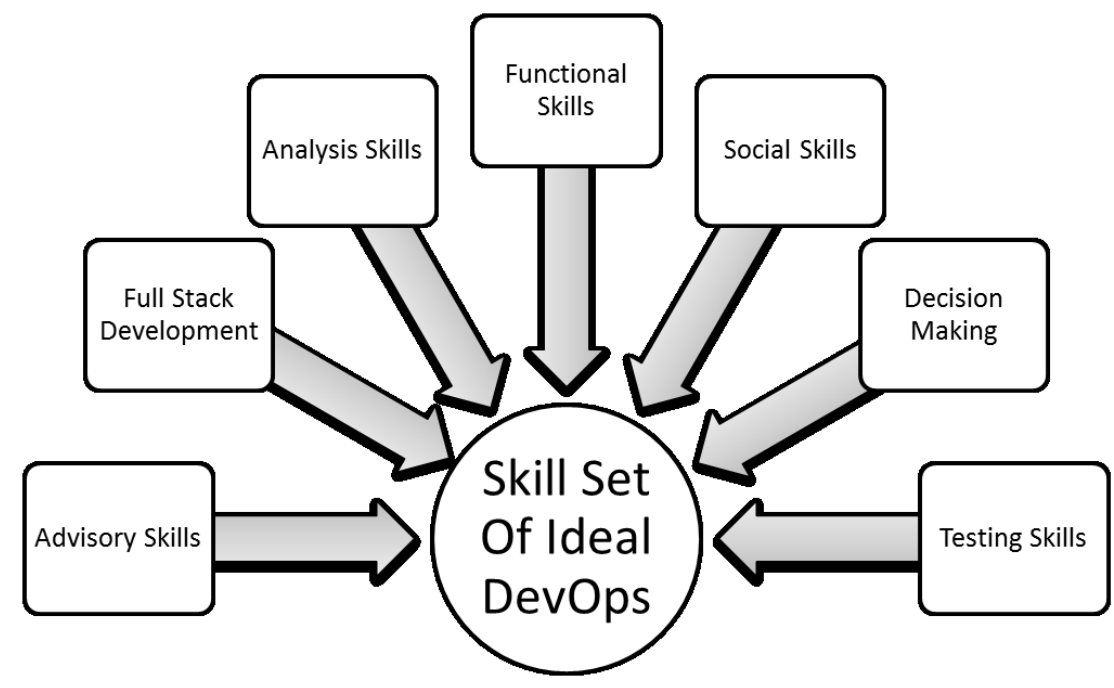

Fig.3. Ideal DevOps Skill Set

\subsection{COMPONENTS OF THE DEVOPS}

The ideal structure characterizing the phenomenon of the DevOps and the magnitudes of the DevOps [10] and the capability of the DevOps and its components involved in it for addressing the complexities and the results attained based on the review is and the literatures gathered is present in the fig. 3 below.

\begin{tabular}{|l|l|}
\hline - Poor Communication \\
- Complexities in managing configurations \\
- Observing of the Data \\
Faced
\end{tabular}


Journal of Information Technology and Digital World (2019)

Vol.01/ No. 01

Pages: 27-37

https://www.irojournals.com/itdw/

DOI: https://doi.org/10.36548/jitdw.2019.1.004

Fig .4 Structures Characterizing the Potent of DevOps [10]

This Paper presents the review on the DevOps along with the challenges and the benefits in it to have a better understanding of the DevOps and have an enhanced Knowledge in the adoption of the DevOps.

The paper below is organized with the necessity and the lifecycle of the DevOps in the section 2, The Fundamentals and the working of the DevOps in the Section 3. The Opportunities and the Challenges of the DevOps in section 4 and the Conclusion in section 5 .

\section{NECESSITY AND THE LIFE CYCLE OF DEVOPS [11]}

Before the emergence of the DevOps, the team of the development and the operation worked in isolation, with no communication in between them. Once the design was completed the testing and the deploying were conducted separately and had different timelines resulting in increased the production time. The lack of the DevOps caused a more time in testing, designing and the deploying. Without DevOps the production was prone to human errors due to the manual coding and had increased latency due to the varying timelines in the coding and the operation. So the increase in the production time, the miscommunication between the teams, error prone coding and the urge to speedy delivery of the software paved way for the necessity of the DevOps. This DevOps showed considerable difference from the Agile and traditional process as it was very promising in enhancing the customer service and the competence in a business. The table. 1 and 2 below shows the comparison of the DevOps with the traditional process and the DevOps with the Agile respectively.

Table.1 Comparison of the DevOps with the Traditional process

ISSN: 2582-418X (online)

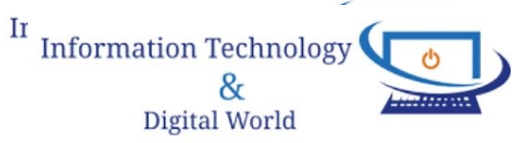




\begin{tabular}{|l|l|}
\hline \multicolumn{1}{|c|}{ Traditional Process } & \multicolumn{1}{|c|}{ DevOps } \\
\hline $\begin{array}{l}\text { Development and the Operation Team Works } \\
\text { separately }\end{array}$ & $\begin{array}{l}\text { Development and the Operation Team Works } \\
\text { Together }\end{array}$ \\
\hline $\begin{array}{l}\text { The Knowledge of the failover, redundancy, } \\
\text { data center, locations and the storage } \\
\text { requirements are misrepresented as no } \\
\text { information are provided fro m the } \\
\text { developers }\end{array}$ & $\begin{array}{l}\text { The Knowledge of the failover, redundancy, } \\
\text { data center, locations and the storage } \\
\text { requirements are accurate as the inputs from } \\
\text { the developers are available }\end{array}$ \\
\hline $\begin{array}{l}\text { The Operation does have any hint of what is } \\
\text { done under the development team }\end{array}$ & $\begin{array}{l}\text { The Operation team is fully aware of the } \\
\text { process under the development team }\end{array}$ \\
\hline $\begin{array}{l}\text { The operation team separately develops a } \\
\text { monitoring plan }\end{array}$ & $\begin{array}{l}\text { The Development and the operation team } \\
\text { joins together and frames the monitoring plan }\end{array}$ \\
\hline $\begin{array}{l}\text { The Testing crashes the application causing } \\
\text { the delay in the go live and release }\end{array}$ & $\begin{array}{l}\text { The testing makes the application bit slow } \\
\text { and the tailbacks in the application are } \\
\text { identified and fixed by the development team } \\
\text { and released in time }\end{array}$ \\
\hline
\end{tabular}

The table. 1 presents the description of the traditional as well as the DevOps Process and the table .2 below gives the details of the difference between the Agile and the DevOps providing the merits of the DevOps against the Agile.

Table.2 Difference between the Agile and the DevOps 
Journal of Information Technology and Digital World (2019)

Vol.01/ No. 01

Pages: 27-37

https://www.irojournals.com/itdw/

DOI: https://doi.org/10.36548/jitdw.2019.1.004

\begin{tabular}{|l|l|}
\hline \multicolumn{1}{|c|}{ DevOps } & \multicolumn{1}{|c|}{ Agile } \\
\hline $\begin{array}{l}\text { It concentrates on the deployment of the } \\
\text { software and the operation team }\end{array}$ & $\begin{array}{l}\text { Stresses on the breaking down of the } \\
\text { blockades between the management and the } \\
\text { developers }\end{array}$ \\
\hline $\begin{array}{l}\text { Focuses on bridging the gap between the } \\
\text { development and the operation. }\end{array}$ & $\begin{array}{l}\text { Focuses on the gap between the customer } \\
\text { requirements and the development teams }\end{array}$ \\
\hline $\begin{array}{l}\text { Pays attention to the operational and the } \\
\text { business readiness }\end{array}$ & $\begin{array}{l}\text { Pays attention to the non-functional and the } \\
\text { functional readiness }\end{array}$ \\
\hline $\begin{array}{l}\text { It deploys the soft ware in a reliable,safest } \\
\text { and a fastest way. }\end{array}$ & $\begin{array}{l}\text { Concentrates the development path } \\
\text { formulated by the organization }\end{array}$ \\
\hline $\begin{array}{l}\text { The skill set is spread in a divide and a } \\
\text { conquer manner between the development } \\
\text { and the operation team }\end{array}$ & $\begin{array}{l}\text { All the team members are trained with the } \\
\text { similar and equal skills. }\end{array}$ \\
\hline $\begin{array}{l}\text { Produces the major releases within a } \\
\text { consolidated deadline than the frequent } \\
\text { releases. }\end{array}$ & $\begin{array}{l}\text { Produces multiple features in a short span of } \\
\text { time. }\end{array}$ \\
\hline
\end{tabular}

The life cycle of the DevOps hold five strides. They are development, Testing, Integration, deployment and the monitoring; the fig. 5 below shows the life cycle and the description of the each stage in the life cycle of the DevOps. A very deep integration is required between the development and the operations; to attain a knowledge that creates an understanding on the DevOps necessitates one to acquire knowledge about the life cycle of the DevOps.

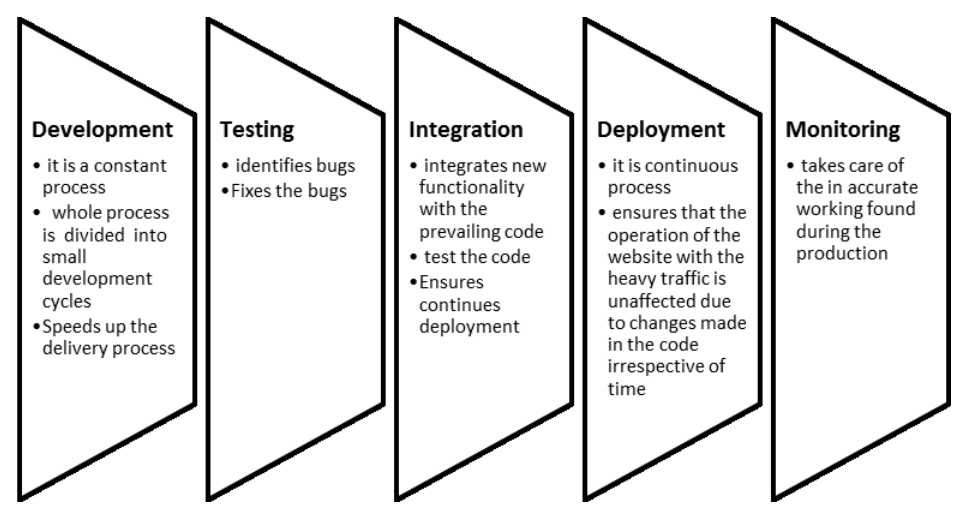

Fig .5 Stages in the DevOps Life Cycle. 
Journal of Information Technology and Digital World (2019)

Vol.01/ No. 01

Pages: 27-37

https://www.irojournals.com/itdw/

DOI: https://doi.org/10.36548/jitdw.2019.1.004

\section{FUNDAMENTALS AND THE WORKING PROCEDURE OF DEVOPS [12]}

The DevOps includes six fundamentals that are vital when adopting the DevOps, they are listed as follows

1. The DevOps work concentrating on the interest of the customers, in order to make them continually invest on their services and the products.

2. The take a life time responsibility to improve the quality of the products that are developed.

3. It mainly focuses on minimizing the waste and to speed up the product development and the services rendered.

4. One of the most vital principles of the DevOps is automation of everything.

5. Work as single team with a perfect co-operation.

6. Follows steps that provide a robust monitoring and the testing procedures.

Moving on the working procedure of the DevOps, it caters a synopsis of the order of the input, and provides details of the operations performed and generates output for the operation performed. It enables to segregate and sequences the task based on the based on the request form the customers and allows reflect the superlative methods in the configuration tasks. The fig. 6 below shows the Work Flow process in the

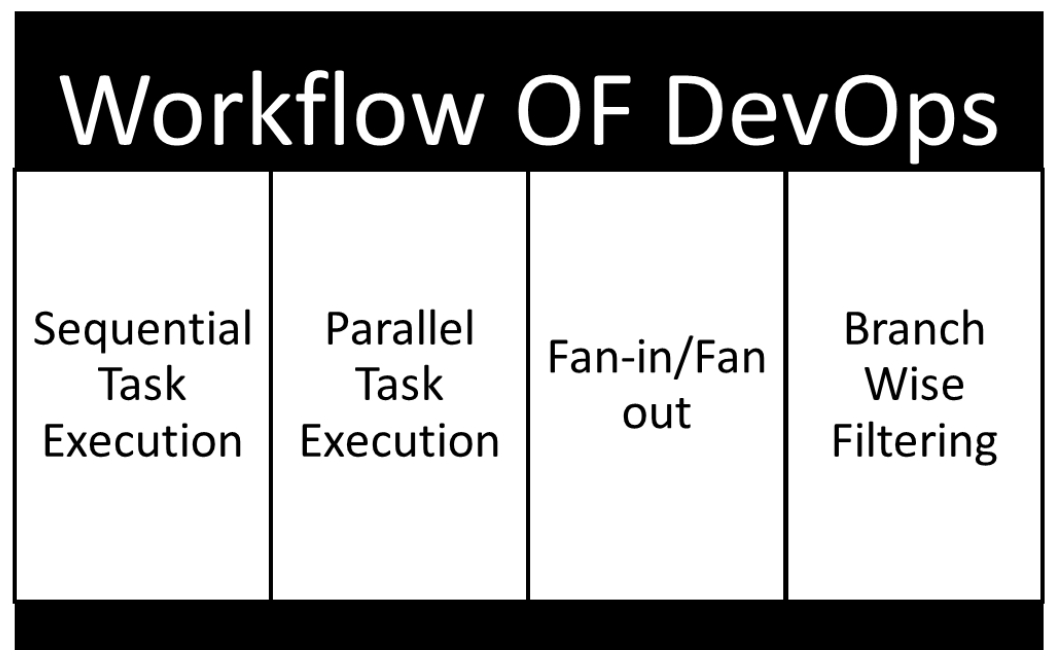

Fig .6 Work Flow of the DevOps 
Vol.01/ No. 01

Pages: 27-37

https://www.irojournals.com/itdw/

DOI: https://doi.org/10.36548/jitdw.2019.1.004

\section{CHALLENGES AND BENEFITS IN DEVOPS}

The Challenges and the benefits of the DevOps based on the literature [3], [4], [5], [7], [10], [13] gathered are presented below in the table. 3

Table .3. Over view of the Benefits and the Challenges of the DevOps

\begin{tabular}{|c|c|}
\hline \multirow[t]{11}{*}{ Benefits } & $\begin{array}{l}\text { Lowers faihure Rate of new products, by QA automated } \\
\text { testing }\end{array}$ \\
\hline & $\begin{array}{l}\text { Restores the eartier version, ensures real time } \\
\text { visualization of the pipeline }\end{array}$ \\
\hline & Does an effortless recovery process \\
\hline & Reduces time to market, rapid delivery \\
\hline & Improves the quality of the application, reduces defects \\
\hline & $\begin{array}{l}\text { Provides a OS with the software with the more stableness, } \\
\text { secureness and audittable changes }\end{array}$ \\
\hline & $\begin{array}{l}\text { Improves the cost efficiency in the development of the } \\
\text { software }\end{array}$ \\
\hline & Improves the speed of the process \\
\hline & Enhances the communication and the collaboration \\
\hline & $\begin{array}{l}\text { Improves the efficiency and minimizes the enror in the } \\
\text { process, by regular feedback and dynamic learning }\end{array}$ \\
\hline & $\begin{array}{l}\text { Develops good working environment, contimuous } \\
\text { imnovation and planning }\end{array}$ \\
\hline \multirow[t]{10}{*}{ Challenges } & Lacks clear definition \\
\hline & Lacks references for the solutions \\
\hline & Does not have a standantized results \\
\hline & Exerts great effort on the data protection \\
\hline & Complexity of the tool integration \\
\hline & Dependence on too many tools \\
\hline & Requires separate toolsets and metrics \\
\hline & $\begin{array}{l}\text { In compatible for mission-critical applications that } \\
\text { inchude bank, power and the other sensitized data sites. }\end{array}$ \\
\hline & Lack of standard repositories \\
\hline & Lacks of service virtualization \\
\hline
\end{tabular}


Journal of Information Technology and Digital World (2019)

Vol.01/ No. 01

Pages: 27-37

https://www.irojournals.com/itdw/

DOI: https://doi.org/10.36548/jitdw.2019.1.004

\section{CONCLUSION}

The DevOps being a trending conception for having a software development that is Agile, it does an automated agile software development and enhances the quality of the product and the customer satisfaction. However the lack of clear understanding about the DevOps has obstructed many organization from adopting the DevOps, so the paper the paper explored the DevOps presenting the necessity of the DevOps, its life cycle, it work flow, its fundamentals, skill sets and components etc. along with the benefits of adopting to it and the challenges prevailing as the obstacle to its adoption. The information provided in the paper would result with the improved prominence of the DevOps causing a lesser risks in adoption to it. In future the paper is to continue with the study on the opportunities of the DevOps in the internet of things.

\section{References}

[1] Zheng, Jiabin, Yan Liu, and Jin Lin. "Exploring DevOps for Data Analytical System with Essential Demands Elicitation." In SEKE, pp. 255-260. 2016.

[2] Jabbari, Ramtin, Nauman bin Ali, Kai Petersen, and Binish Tanveer. "What is devops?: A systematic mapping study on definitions and practices." In Proceedings of the Scientific Workshop Proceedings of XP2016, p. 12. ACM, 2016.

[3] Bou Ghantous, G., and Asif Gill. "DevOps: Concepts, Practices, Tools, Benefits and Challenges." PACIS2017 (2017).

[4] Crowley, Catherine, Laura McQuillan, and Conor O'Brien. "Understanding DevOps: Exploring the origins, composition, merits, and perils of a DevOps Capability." In Proceedings of the 4th International Conference on Production Economics and Project Evaluation, ICOPEV 2018, Guimarães, Portugal, pp. 29-37. University of Minho, 2018.

[5] Lwakatare, Lucy Ellen, Pasi Kuvaja, and Markku Oivo. "An exploratory study of devops extending the dimensions of devops with practices." ICSEA 2016104 (2016).

[6] Moore, John, Gerd Kortuem, Andrew Smith, Niaz Chowdhury, Jose Cavero, and Daniel Gooch. "DevOps for the urban IoT." In Proceedings of the Second International Conference on IoT in Urban Space, pp. 78-81. ACM, 2016.

[7] Limoncelli, Thomas A., and Doug Hughe. "LISA'11 Theme-DevOps: New Challenges, Proven Values." USENIX; login: Magazine 36, no. 4 (2011).

[8] Wiedemann, Anna, and Manuel Wiesche. "Are you ready for Devops? Required skill set for Devops teams." In Proceedings of the European Conference on Information Systems. 2018.

[9] Kang, Hui, Michael Le, and Shu Tao. "Container and microservice driven design for cloud infrastructure devops." In 2016 IEEE International Conference on Cloud Engineering (IC2E), pp. 202-211. IEEE, 2016. 
Journal of Information Technology and Digital World (2019)

Vol.01/ No. 01

Pages: 27-37

https://www.irojournals.com/itdw/

DOI: https://doi.org/10.36548/jitdw.2019.1.004

[10] Lwakatare, Lucy Ellen, Pasi Kuvaja, and Markku Oivo. "Dimensions of devops." In International conference on agile software development, pp. 212-217. Springer, Cham, 2015.

[11] Elliot, Stephen. "DevOps and the cost of downtime: Fortune 1000 best practice metrics quantified." International Data Corporation (IDC) (2014).

[12] Mohamed, S. "DevOps maturity calculator DOMC-value oriented approach." International Journal of Engineering Science and Research 2, no. 2 (2016): 25-35.

[13] Basher, Mohamed. "DevOps: An explorative case study on the challenges and opportunities in implementing Infrastructure as code." (2019).

[14] Diel, Elisa, Sabrina Marczak, and Daniela S. Cruzes. "Communication challenges and strategies in distributed devops." In 2016 IEEE 11th International Conference on Global Software Engineering (ICGSE), pp. 24-28. IEEE, 2016.

[15] Meirosu, C., A. Manzalini, J. Kim, R. Steinert, Sachin Sharma, G. Marchetto, I. Papafili, K. Pentikousis, and S. Wright. "DevOps for software-defined telecom infrastructures." INTERNET ENGINEERING TASK FORCE (IETF) (2015): 1-20. 